\title{
Lavandulyl Flavanones from Sophora flavescens Protect Mouse Hippocampal Cells against Glutamate-Induced Neurotoxicity via the Induction of Heme Oxygenase-1
}

\author{
Gil-Saeng Jeong, ${ }^{\#, a}$ Bin Li, ${ }^{\#, b}$ Dong-Sung LeE, ${ }^{b}$ Erisa Byun, ${ }^{b}$ Ren-Bo AN, ${ }^{c}$ Hyun-Ock PAE, ${ }^{d}$ \\ Hun-Taeg Chung, ${ }^{d}$ Kwon-Ha Youn, ${ }^{a}$ and Youn-Chul KIM ${ }^{*}, b$ \\ ${ }^{a}$ Institute for Radiological Imaging Science, Wonkwang University; ${ }^{b}$ College of Pharmacy, Wonkwang University; Iksan \\ 570-749, Korea: ${ }^{c}$ College of Pharmacy, Yanbian University; Yanji, Jilin 133000, China: and ${ }^{d}$ Department of \\ Microbiology and Immunology, Wonkwang University School of Medicine; Iksan 570-749, Korea. \\ Received January 25, 2008; accepted July 1, 2008; published online July 2, 2008
}

Lavandulyl flavanones of Sophora flavescens roots are anti-malarial, anti-inflammatory, and cytotoxic. Here, we examined whether four lavandulyl flavanones, (2S)-2'-methoxykurarinone (1), sophoraflavanone G (2), leachianone A (3), and (-)-kurarinone (4), isolated from $S$. flavescens could protect HT22 immortalized hippocampal cells against glutamate-induced oxidative stress. Compounds 1 and 2 induced the expression of heme oxygenase (HO)-1 and increased HO activity dose- and time-dependently. These two compounds also suppressed glutamateinduced reactive oxygen species generation in HT22 cells, whereas compounds 3 and 4 were not protective. These two lavandulyl flavanones (compounds 1, 2) may protect against glutamate-induced neurotoxicity via HO-1 induction.

Key words lavandulyl flavanone; Sophora flavescens; heme oxygenase-1; HT22; cytoprotection; glutamate

Oxidative stress, or the accumulation of reactive oxygen species (ROS), is important in the pathogenesis of neurodegenerative disorders such as Alzheimer's disease, Parkinson's disease, Huntington's disease, and ischemia. ${ }^{1-4)}$ Cell toxicity occurs when the systems to generate and scavenge ROS are out of balance. Glutamate also induces oxidative stress by inhibiting the cellular uptake of cystine via the cystine/ glutamate transport system, $\mathrm{x}_{\mathrm{c}}^{-}$, leading to depletion of glutathione, increased ROS production, and elevated $\mathrm{Ca}^{2+}$ levels. ${ }^{2,5)}$ Heme oxygenase (HO) protects against oxidative injury following the degradation of oxidative heme to biliverdin, free iron, and carbon monoxide. $\left.{ }^{6}\right)$ Subsequently, biliverdin is rapidly metabolized into bilirubin by cytosolic biliverdin reductase, and free iron is sequestered by ferritin. ${ }^{6}$ Two isoforms, HO-2 and HO-3 are constitutively expressed, but HO-1 is inducible in many cell types, including neuronal cells. $^{7-9)} \mathrm{HO}-1$ can protect against glutamate toxicity in HT22 cells. ${ }^{10,11)}$

The root of Sophora flavescens Aiton (Leguminosae) is an oriental herbal medicine used as a diuretic and for the treatment of jaundice, leucorrhea, carbuncles, pyogenic infections of the skin, scabies, enteritis, and dysentery. ${ }^{12)}$ Phytochemical studies of $S$. flavescens have reported the isolation of quinloizidine alkaloids, flavonoids, and triterpenoids. ${ }^{13)} \mathrm{We}$ previously isolated four lavandulyl flavanones, (2S)-2'methoxykurarinone (1), sophoraflavanone G (2), leachianone A (3), and (-)-kurarinone (4) from this plant. ${ }^{14)}$ Lavandulyl flavanones are rare in the plant kingdom and they are mainly found in Sophora species. This uniqueness prompted us to evaluate their protective effects against glutamate-induced oxidative injury in mouse hippocampal HT22 cells.

\section{MATERIALS AND METHODS}

Materials Dulbecco's modified Eagle's medium (DMEM), fetal bovine serum (FBS), and antibiotics were obtained from Gibco BRL (Gaithersburg, MD, U.S.A.). The BCA protein assay kit was from Pierce (Rockford, IL, U.S.A.). Horseradish peroxidase-conjugated secondary antibodies were from Santa Cruz Biotechnology, Inc. ECL substrate solution was from Amersham Pharmacia Biotech (Piscataway, NJ, U.S.A.). Tin protoporphyrin IX (SnPP IX), an inhibitor of HO activity, was obtained from Porphyrin Products (Logan, UT, U.S.A.). 3'-(4,5-Dimethylthiazol-2-yl)-2,5-diphenyltetrazolium bromide (MTT) and all other chemicals were obtained from Sigma Chemical Co. (St. Louis, MO, U.S.A.). Four lavandulyl flavanones, (2S)-2'-methoxykurarinone, sophoraflavanone $\mathrm{G},(-)$-kurarinone, and leachianone A, were isolated and identified from the root of $S$. flavescens in our previous study. ${ }^{14)}$

Cell Culture Mouse hippocampal HT22 cells, a subclone of the HT4 hippocampal cell line, were obtained from Prof. Inhee-Mook (Seoul National University, Seoul, Korea). The cells were maintained at $5 \times 10^{5}$ cells $/ \mathrm{ml}$ in DMEM medium supplemented with $10 \%$ heat-inactivated FBS, penicillin $\mathrm{G}$ (100 units $/ \mathrm{ml})$, streptomycin $(100 \mathrm{mg} / \mathrm{ml})$, and L-glutamine $(2 \mathrm{~mm})$, and incubated at $37^{\circ} \mathrm{C}$ in a humidified atmosphere containing $5 \% \mathrm{CO}_{2}$ and $95 \%$ air

Cell Viability HT22 cells were initially pretreated with compounds or CoPP, an inducer of $\mathrm{HO}$ activity, for $1 \mathrm{~h}$ in the absence or presence of SnPP, an inhibitor of HO activity. The cells were then exposed to glutamate $(5 \mathrm{mM})$ for $12 \mathrm{~h}$ followed by an assessment of cell viability. Cell viability was determined using the MTT assay. Briefly, cells were incubated with MTT $(0.5 \mathrm{mg} / \mathrm{ml})$ for $2 \mathrm{~h}$ at $37^{\circ} \mathrm{C}$, medium was discarded, acidic isopropanol $(0.04 \mathrm{~N} \mathrm{HCl})$ was added, and after incubating for $30 \mathrm{~min}$, absorbance was measured at $595 \mathrm{~nm}$ using a microplate reader (BIO-RAD, Hercules, CA, U.S.A.).

Western Blotting Analysis for HO-1 Expression After treatment, HT22 cells $\left(3 \times 10^{6}\right.$ cells $/ 3 \mathrm{ml}$ in $60 \mathrm{~mm}$ dish) were collected and washed with phosphate-buffered saline (PBS). After centrifugation, cell lysis was performed at $4{ }^{\circ} \mathrm{C}$ by vigorous shaking for $15 \mathrm{~min}$ in RIPA buffer [ $150 \mathrm{~mm} \mathrm{NaCl}, 1 \%$ NP- $40,0.5 \%$ sodium deoxycholate, $0.1 \%$ sodium dodecyl 
sulfate (SDS), $50 \mathrm{~mm}$ Tris- $\mathrm{HCl}$ (pH 7.4), $50 \mathrm{~mm}$ glycerophosphate, $20 \mathrm{~mm} \mathrm{NaF}, 20 \mathrm{~mm}$ ethylene glycol bis(2aminoethyl ether)- $N, N, N^{\prime}, N^{\prime}$-tetra acetic acid (EGTA), $1 \mathrm{~mm}$ DTT, $1 \mathrm{~mm} \mathrm{Na} \mathrm{VO}_{4}$, and protease inhibitors]. After centrifugation at $14800 \mathrm{~g}$ for $15 \mathrm{~min}$, the supernatant was separated and stored at $-70^{\circ} \mathrm{C}$ until use. The protein concentration was determined using the BCA protein assay kit. After addition of sample loading buffer, protein samples were separated on a $12.5 \%$ SDS-polyacrylamide gel. Proteins were transferred to polyvinylidene difluoride blots at $300 \mathrm{~mA}$ for $6 \mathrm{~h}$. The blots were blocked for $1 \mathrm{~h}$ at room temperature in fresh blocking buffer $(0.1 \%$ Tween 20 in Tris-buffered saline, $\mathrm{pH}$ 7.4 , containing $5 \%$ non-fat dried milk). Dilution (1:1000) of primary antibodies was made in PBS with $3 \%$ non-fat dried milk. Following three washes with PBST (PBS and $0.1 \%$ Tween 20), the blots were incubated with horseradish peroxidase-conjugated secondary antibodies in PBS with 3\% nonfat dried milk for $1 \mathrm{~h}$ at room temperature. The blots were washed again three times in PBST buffer, and transferred proteins were incubated with ECL substrate solution for $1 \mathrm{~min}$ according to the manufacturer's instructions, followed by visualization with X-ray film.

HO Activity Assay HO enzyme activity was measured by a method previously described. ${ }^{15)}$ Briefly, microsomes from harvested cells were added to a reaction mixture containing nicotinamide adenine dinucleotide phosphate, biliverdin reductase from rat liver cytosol, and the substrate hemin. The reaction was conducted at $37^{\circ} \mathrm{C}$ in the dark for $1 \mathrm{~h}$, terminated by the addition of $1 \mathrm{ml}$ of chloroform, and extracted bilirubin was calculated by the difference in absorbance between 464 and $530 \mathrm{~nm}$.

ROS Measurement For measurement of ROS, HT22 cells $\left(2.5 \times 10^{4}\right.$ cells $/ \mathrm{ml}$ in 24 -well plates $)$ were treated with $5 \mathrm{~mm}$ glutamate in the presence or absence of four lavandulyl flavanones or SnPP (HO inhibitor) and incubated for $8 \mathrm{~h}$. After washing with PBS, the cells were stained with $10 \mu \mathrm{M}$ DCFDA in Hanks' balanced salt solution for $30 \mathrm{~min}$ in the dark. Cells were then washed twice with PBS and extracted with $1 \%$ Triton $\mathrm{X}-100$ in PBS for $10 \mathrm{~min}$ at $37^{\circ} \mathrm{C}$. Fluorescence was recorded with an excitation wavelength of $490 \mathrm{~nm}$ and an emission wavelength of $525 \mathrm{~nm}$ (Spectramax Gemini XS; Molecular Devices, Sunnyvale, CA, U.S.A.).

Statistical Analysis Data are expressed as the mean \pm S.D. of at least three independent experiments. The results were compared using one-way ANOVA and Turkey's multiple comparison test. Statistical analysis was performed with the GraphPad Prism software version 3.03 (GraphPad Software Inc., San Diego, CA, U.S.A.).

\section{RESULTS AND DISCUSSION}

We first investigated whether four lavandulyl flavanones (Chart 1) affected HO-1 protein expression by treating HT22 cells for $12 \mathrm{~h}$ with compounds $\mathbf{1}-\mathbf{4}$. Compounds $\mathbf{1}$ and 2 dose-dependently increased $\mathrm{HO}-1$ expression at $6 \mathrm{~h}$ and peaked at $18 \mathrm{~h}$ after treatment (Fig. 1A), whereas compounds $\mathbf{3}$ and $\mathbf{4}$ did not, despite their structural similarities to $\mathbf{1}$ and $\mathbf{2}$ (data not shown). Compounds $\mathbf{1}$ and $\mathbf{2}$ also increased bilirubin levels, a marker of $\mathrm{HO}$ activity (Fig. 1B, $p<0.05$ ), whereas compounds $\mathbf{3}$ and $\mathbf{4}$ did not (data not shown). None of the compounds were cytotoxic (data not shown).

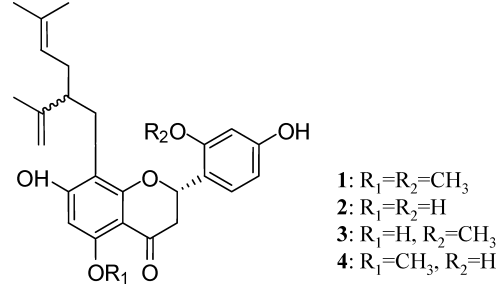

Chart 1. The Structures of Compounds $\mathbf{1}-\mathbf{4}$

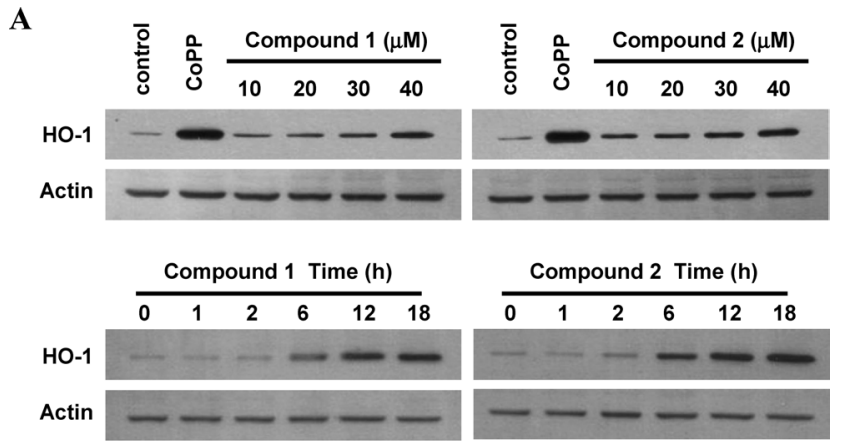

$\mathbf{B}$

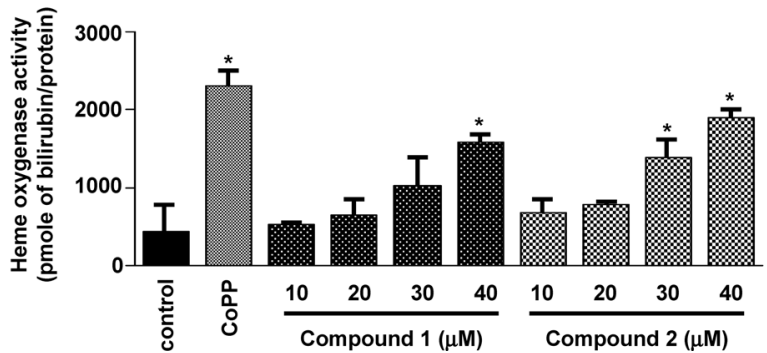

Fig. 1. Effects of Compounds $\mathbf{1}$ and $\mathbf{2}$ on HO-1 Expression and Activity in HT22 Cells

(A) Cells were incubated for $12 \mathrm{~h}$ with compounds $\mathbf{1}$ and $\mathbf{2}$ (upper layer). Cells were incubated for indicated periods with $40 \mu \mathrm{m}$ of compounds $\mathbf{1}$ and 2. Expression of HO-1 (A) was determined by Western blot analysis, and representative blots of three independent experiments are shown. (B) HO activity was determined via bilirubin formation. Each bar represents the mean \pm S.D. of three independent experiments. $* p<0.05$ $v s$. control.

Pretreatment with compounds $\mathbf{1}$ and $\mathbf{2}$ for $2 \mathrm{~h}$ protected HT22 cells from glutamate-mediated toxicity, whereas compounds 3 and $\mathbf{4}$ did not (Fig. 2A). Compounds $\mathbf{1}$ and $\mathbf{2}$ also effectively suppressed glutamate-induced ROS generation, but compounds 3 and $\mathbf{4}$ did not (Fig. 2B).

HO-1 can protect against glutamate-induced oxidative injury in HT22 cells. ${ }^{11,16,17)}$ We therefore co-treated cells with compounds 1 and $\mathbf{2}$ and SnPP, an inhibitor of HO activity. SnPP significantly inhibited the protective activity of compounds 1 and 2 (Fig. 3A), and treatment with the HO-1 inducer, CoPP, showed comparable protection to the two compounds (Fig. 3A). Furthermore, the induction of HO-1 expression was required to suppress glutamate-induced ROS generation (Fig. 3B).

Glutamate cytotoxicity contributes to neuronal degeneration in central nervous system (CNS) diseases such as epilepsy and ischemia. Glutamate cytotoxicity is mediated by receptor-initiated excitotoxicity and non-receptor-mediated oxidative stress. ${ }^{5,18)}$ Excitotoxicity refers to an excessive activation of neuronal amino acid receptors, and glutamateinduced excitotoxicity mediates neuronal death in many dis- 
A
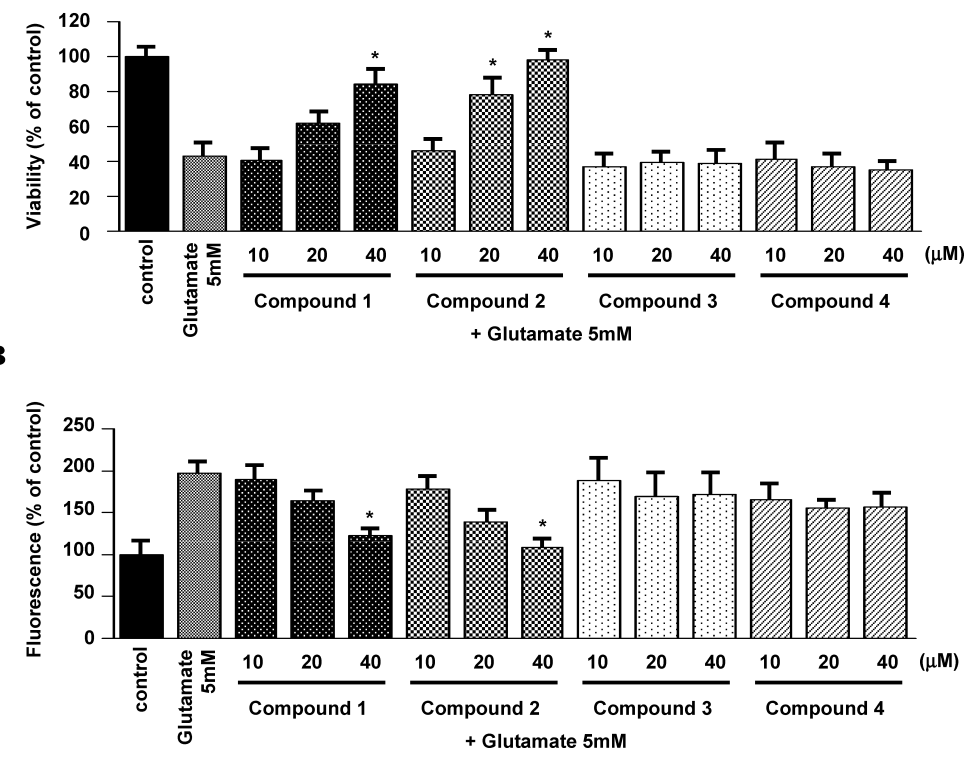

Fig. 2. Effects of Compounds $\mathbf{1}-\mathbf{4}$ on Glutamate-Induced Oxidative Neurotoxicity and Inhibition of ROS Generation

(A) Cells were treated with compounds 1 and $\mathbf{2}$ and then incubated for $12 \mathrm{~h}$ with glutamate $(5 \mathrm{~mm})$. Each bar represents the mean \pm S.D. of three independent experiments. $* p<0.05$ vs. control (B) Exposure of HT22 cells to $5 \mathrm{mM}$ glutamate for $12 \mathrm{~h}$ increased ROS production. Each bar represents the mean \pm S.D. of three independent experiments. $* p<0.05$ vs. glutamate $(5 \mathrm{~mm})$.

A

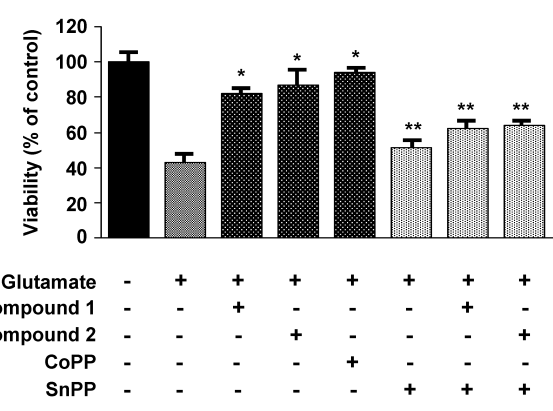

B

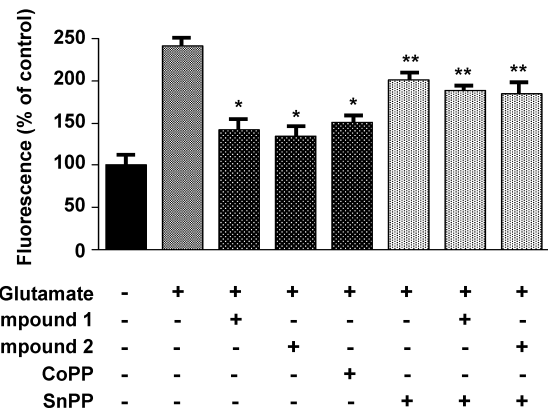

Fig. 3. Effects of HO-1 Induction by Compounds $\mathbf{1}$ and $\mathbf{2}$ on GlutamateInduced Oxidative Neurotoxicity and ROS Generation

(A) Cells were treated with various combinations of $40 \mu \mathrm{M}$ of compounds $\mathbf{1}$ and $\mathbf{2}$, $20 \mu \mathrm{M}$ CoPP, and $50 \mu \mathrm{M}$ SnPP and then exposed to glutamate $(5 \mathrm{~mm})$ for $12 \mathrm{~h}$. Each bar represents the mean \pm S.D. of three independent experiments. $* p<0.05 v s$. glutamate $(5 \mathrm{~mm}), * * p<0.05 v s$. the same treatment plus SnPP. (B) Exposure of HT22 cells to $5 \mathrm{~mm}$ glutamate for $12 \mathrm{~h}$ increased ROS production. Each bar represents the mean \pm S.D. of three independent experiments. $* p<0.05 v s$. glutamate $(5 \mathrm{~mm}), * * p<0.05 v s$. the same treatment plus SnPP.

orders. ${ }^{18,19)}$ The immortalized mouse hippocampal cell line, HT22, phenotypically resembles neuronal precursor cells but lacks functional ionotropic glutamate receptors, thus excluding excitotoxicity as a cause for glutamate triggered cell death. ${ }^{20,21)}$ Therefore, HT22 cells are a useful model for studying oxidative glutamate toxicity.
The inducible HO-1 is a rate-limiting enzyme in heme catabolism, leading to the formation of carbon monoxide, iron, and biliverdin. Biliverdin and bilirubin (a product from biliverdin from biliverdin reductase) protect CNS neurons ${ }^{22)}$ and HT22 cells ${ }^{17)}$ against oxidative stress. HO-1 induction by low-molecular weight compounds might play an important role in the neuroprotection of CNS neurons. ${ }^{17)}$ In addition, HO-1 protein reduces glutamate-toxicity by decreasing the levels of ROS in mouse neurons. ${ }^{23)}$

In the present study, we demonstrated that two compounds $(1,2)$ of four lavandulyl flavanones isolated from $S$. flavascens up-regulate HO-1 expression and activity in a concentration- and time-dependent manner. Compounds $\mathbf{1}$ and $\mathbf{2}$ protected against oxidant-mediated cell injury via induction of HO-1. Despite structural similarities, compounds 3 and $\mathbf{4}$ did not stimulate HO-1 expression, ROS scavenging, or cytoprotection. Although, it is not clear whether these compounds can cross the blood-brain barrier or achieve concentrations in the brain, these compounds may be useful as potential neuroprotective agents.

Acknowledgements This paper was supported by Wonkwang University in 2007.

\section{REFERENCES}

1) Behl C., Davis J. B., Lesley R., Schubert D., Cell, 77, 817-827 (1994).

2) Coly J. T., Puttfarcken P., Science, 262, 689-695 (1993).

3) Simonian N. A., Coly J. T., Annu. Rev. Pharmacol., 36, 83-106 (1996).

4) Makkesbery W. R., Free Radic. Biol. Med., 23, 134-147 (1997).

5) Murphy T. H., Miyamoto M., Sastre A., Schnaar R. L., Coly J. T., Neuron, 2, 1547-1558 (1989).

6) Kikuchi G., Yoshida T., Noguchi M., Biochem. Biophys. Res. Commun., 338, 558-567 (2005). 
7) Moon M. K., Choi B. M., Oh G. S., Pae H. O., Kim J. D., Oh H., Oh C. S., Kim D. H., Rho Y. D., Shin M. K., Lee H. S., Chung H. T., Toxicol. Lett., 145, 46-54 (2003).

8) Pertusa M., Garcia-Matas S., Rodriguez-Farre E., Sanfeliu C., Cristofol R., J. Neurochem., 101, 794-805 (2007).

9) Song L., Song W., Schipper H. M., J. Neurosci. Res., 85, 2186-2195 (2007).

10) Fu Y., Koo M. W., Neurotox. Res., 10, 23-30 (2006).

11) Rossler O. G., Bauer I., Chung H. Y., Thiel G., Neurosci. Lett., 362 , 253-257 (2004)

12) Chang H. M., But P. P. H., "Pharmacology and Applications of Chinese Materia Medica," World Scientific Publishers, Singapore, 1986 , p. 736.

13) Tang W., Eisenbrand G., "Chinese Drugs of Plant Origins," SpringerVerlag, New York, 1992, p. 931.

14) Kang T. H., Jeong S. J., Ko W. G., Kim N. Y., Lee B. H., Inagaki M.,
Miyamoto T., Higuchi R., Kim Y. C., J. Nat. Prod., 63, 680-681 (2000).

15) Tenhunen R., Marver H. S., Schmid R., J. Lab. Clin. Med., 75, 410 421 (1970).

16) Satoh T., Ishige K., Sagara Y., Neurosci. Lett., 371, 1-5 (2004).

17) Satoh T., Baba M., Nakatsuka D., Ishikawa Y., Aburatani H., Furuta K., Ishikawa T., Hatanaka H., Suzuki M., Watanabe Y., Eur. J. Neurosci., 17, 2249-2255 (2003).

18) Choi D. W., Neuron, 1, 623-634 (1988).

19) Mattson M. P., Nat. Rev. Mol. Cell Biol., 1, 120-129 (2000).

20) Maher P., Schubert D., Cell. Mol. Life Sci., 57, 1287-1305 (2000).

21) Maher P., Davis J. B., J. Neurosci., 16, 6394-6401 (1996).

22) Dore S., Takahashi M., Ferris C. D., Hester L. D., Guastella D., Snyder S. H., Proc. Natl. Acad. Sci. U.S.A., 96, 2445-3450 (1999).

23) Chen K., Gunter K., Maines M. D., J. Neurochem., 75, 304-313 (2000). 